\title{
Recognition and Justice? Conceptualizing Support for Women Whose Children Are in Care or Adopted
}

\author{
Janet Boddy $1, * \mathbb{C}$ and Bella Wheeler ${ }^{2}$ \\ 1 Centre for Innovation and Research in Childhood and Youth, University of Sussex, Brighton BN1 9QQ, UK \\ 2 Regent's College London, London W1W 5BD, UK; bella.wheeler@rcl.ac.uk \\ * Correspondence: j.m.boddy@sussex.ac.uk
}

Received: 21 September 2020; Accepted: 1 December 2020; Published: 2 December 2020

check for updates

\begin{abstract}
This paper examines the views of mothers who have experienced (or are judged to be at risk of) recurrent removal of children into care or adoption. Drawing on their accounts of working with an intensive 18 month support program called Pause, we argue for the relevance of conceptualizing policy and practice with reference to Honneth's theory of recognition and Fraser's arguments about the need to address misrecognition through redistribution, attending to gendered political and economic injustice. The analysis draws on qualitative longitudinal interviews with 49 women, conducted as part of a national UK Department for Education (DfE)-funded evaluation of Pause. Each woman was interviewed up to four times over a period of up to 20 months, both during and after the Pause intervention. Case-based longitudinal analysis illuminates how stigma can obscure women's rights and needs-including welfare entitlements and health, as well as rights to family life-and shows how support can act to enable both redistribution, advocating to ensure women's rights in a context of diminishing public welfare, and recognition, challenging stigmatization through recognition of women's motherhood, and of their rights to care, solidarity, respect and fun.
\end{abstract}

Keywords: children in care; adoption; stigma; welfare rights; motherhood; family; health; intervention; evaluation

\section{Introduction}

'Understanding the wounds of stigma as social and political injuries can assist in the forging of networks of care and solidarity'. [1] (p. 29)

Rates of children entering care in England have increased significantly over the last two decades. 'Census day' care population data (recording the number of children in care on 31 March in a given year) show that numbers grew from 43 to 64 per 10,000 children in the period 1994-2017. Patterns of change are complex, and whilst the biggest increase has been in the proportion of young people entering care aged 16 years or older, there has also been a marked increase in the number of children who are 'born into care', removed from their mothers very soon after birth [2,3]. Government data on placements through care orders and voluntary accommodation show that the rate of children entering care at birth has almost doubled over ten years, 'from one baby in every 386 live births in 2007-8 to one in 210 in 2017-8' [3] (p. 3). The emphasis in English legislation (notably, the Children Act 1989) is on supporting children's upbringing within their birth families wherever possible, with high thresholds for intervention, and child removal mandated only when there is significant risk of harm to a child. The reasons for growth in rates of care entry are complex, although there is evidence that increasing socio-economic pressures on family lives contribute to risk, as levels of neighborhood deprivation correspond to rates of statutory child protection involvement and of care entry (including for newborns) [3,4]. Bywaters and colleagues [4] attribute these findings to factors including increased 
poverty and inequalities as well as cuts to preventive services, within a child protection system that Featherstone et al. [5] describe as shaming, punitive and neglectful.

Within a wider context of welfare austerity, a punitive framing of child protection can also be seen as politically expedient. Problems are framed as located within the parent (more specifically, the mother), shifting attention away from the failures of state support for family lives, thus 'ultimately holding women accountable for the wellbeing of the nation and for poverty, crimes and other social ills that may threaten this' [6] (p. 131). As Tyler [1] (p. 165) writes, austerity politics have been implemented through state-crafted stigma, with a political economy of disgust providing justification for a program of welfare cuts with 'disproportionate impacts [ ... ] on those already on the losing end of the British class society'.

Tyler's [1] comments are highly relevant to understanding the experiences of women who have had children removed from their care. For these women-and especially those who have experienced recurrent child removals - the toxic triad of shame, punishment and neglect that Featherstone and colleagues [5] describe is likely to be particularly acute, and this contributes to future risks for these women and any subsequent children. Broadhurst and colleagues' landmark analyses of CAFCASS data on 65,000 family court proceedings $[7,8]$ demonstrated the prevalence of recurrent child removals: one in four women whose children are removed through care proceedings is likely to return to the family court with subsequent children. This analysis documented that women in recurrent proceedings were often young when they had their first child ( $45 \%$ were under 20 years) and most had histories of significant complex trauma. Approximately $40 \%$ had been in care themselves as children (and late care entry and multiple placement moves were reported by half), and at least two-thirds had experienced abuse and/or neglect in childhood. This research also revealed how the collateral consequences of child removal increase risks for recurrence [9-11], highlighting the need for policy and services to respond to the support needs of mothers as well as the risks for their children.

Broadhurst and Mason [10] document the ways in which the trauma of child removal in the absence of support exacerbates risk in other aspects of women's lives, both in terms of the immediate psychosocial crisis that follows the loss of a child, and in the enduring and cumulative effects, including impacts on welfare entitlements-for example, when housing benefits are reduced through the so-called 'bedroom tax' when a child's room becomes a 'spare room' ${ }^{1}$. They give the example of one woman in the study who was forced to move from a two-bedroom home into a hostel, where she was living among drug users and subsequently became addicted herself. This research also shows how stigma 'plays out in multiple settings for this group of women-who feel discredited in both interpersonal and professional encounters' [10] (p. 15), noting that a sense of being pre-judged could contribute to women's isolation and make it more difficult for them to access support. Schofield and colleagues' research with parents of children in foster care similarly documented their fear (and experiences) of 'being seen as, or even having become, a 'different' as well as unworthy person' [12] (p. 83). These findings resonate with Tyler's [1] (p. 211) observations about the ways in which 'shame lives on the eyelids': stigma shapes both the ways in which we see and are seen.

As the prevalence of recurrent care proceedings has been recognized, a growing number of targeted initiatives have been developed to intervene with this population of women, aiming to reduce the likelihood that they will have further children who are removed into care or adoption. The value of these services has been documented through independent evaluations (e.g., [13-16]). The provision that was the focus of our research-Pause-was one of the first recurrence-focused services to be established in England. Pause practices deliver intensive, individually-tailored practitioner support over an 18 month period to women who have experienced, or are judged to be at risk of, recurrent removal of children. Pause was initially developed in the London Borough of Hackney in 2013, but has

1 In April 2013, the English government reduced housing benefit payments for households deemed to have one or more 'spare bedrooms'; the result was a reduction in housing benefit of $14 \%$ for one 'spare' room. 
grown into a national organization, supported through substantial investment from government, within the Department for Education's Innovation Programme. In 2015, Pause was awarded £4.2 m in Round 1 of the Innovation Programme to expand its intervention support package to seven areas nationally, and in 2017, Pause was allocated a further $£ 6.8 \mathrm{~m}$ in Round 2 of the DfE Innovation Programme, to scale up and roll out the model to nine other areas and develop and implement a care leaver pilot that targets care-experienced women (aged 16-25) who have had one or more children removed. The analysis presented here draws on data collected for an evaluation of Pause, funded through Round 2 of the Innovation Programme [17]; an earlier evaluation examined the work of Pause through Round 1 funding [16].

The Pause theory of change is predicated on trauma-informed intensive relationship-based practice, driven by women's own perceived needs and priorities. Practitioners have small caseloads (up to eight women) and work flexibly and responsively to facilitate change, supported by a dedicated budget allocation for each woman, designed to 'ensure that practitioners are able to, where necessary, pay for things that might otherwise not be available through normal services' [18] (p. 32). The relationship with the practitioner is at the center of the intervention, generating space for change through 'an intensive and tenacious bespoke support package', aimed at three key areas of work. The first is stabilizing lives, for example, through domestic abuse support; income review and support to take up benefits and address debt; support to access safe and secure housing; support to reduce alcohol or drug misuse; support to reduce offending; support to engage in learning or work. Second, Pause work is focused on developing a sense of self, for example, through one-to-one and group activities designed to build strengths, develop new skills and explore new experiences, as well as support to address bereavement and loss and to establish positive relationships. Within the Pause framework [18] (p. 18) this relationship-based practice is framed as therapeutic, aiming to enable women with significant histories of complex trauma 'to develop an alternative, richer narrative about the woman which does not define her by the (often) "problem saturated" stories of herself as a mother or her own experiences of childhood'. Third, participation in the program entails accessing effective contraception and regular sexual health check-ups. This last criterion relates to a distinctive feature of the Pause model, contraceptive conditionality: this means that support is contingent on women's agreement to use a method of long-acting reversible contraception (LARC) unless this is contra-indicated for medical reasons. This approach is explained as follows in the Pause framework [18] (p. 8):

'As a condition of beginning this voluntary programme, women agree to use the most effective reversible methods of contraception; [ . . . ] Long Acting Reversible Contraception (LARC) so they have the opportunity to reflect and focus on their own needs, often for the first time in their lives.'

Women's contraceptive use raises complex considerations. As Cox [19] (p. 556) observed, effective contraception is fundamental to enabling women to take control of their fertility and hence their reproductive rights, and 'permanent adoptions resulting from repeat care proceedings [also] allow the state to limit marginalized women's reproductive autonomy'. Other models of intervention with women who have experienced repeat removals of children into care or adoption may not use conditionality, but nonetheless strongly encourage use of long-acting reversible contraception [20]. However, ethics concerns have been raised about contraceptive conditionality for vulnerable women with significant support needs: there is a critical distinction between supporting universal access to reproductive health services and targeting specific groups or individuals with the aim of preventing them becoming pregnant [21]. Morriss [11] (p. 821) comments on the ways in which political stigma is written on women's bodies, such that, 'controlling the reproductive lives of working class mothers in ways which curtail future claims upon the state is construed as a policy solution to the imagined (moral) problem of their 'failed parenting' and 'welfare dependency". Pause have engaged with these debates and at the time of writing are undertaking an internal review of their work on sexual and reproductive health, including contraception. 
More broadly, ethical debates about care and control highlight the need for critical reflection on approaches to state intervention in the context of stigma. Research in the field of recurrent child removal (as discussed above) provides stark evidence of the impacts for women and children of lack of timely and appropriate support through their lives. The question for these women is not of whether support is needed, but rather, how such support should be conceptualized and enacted. To paraphrase Tyler's [1] epigraph that opened this article, how should services respond to the social and political wounds of stigma in order to support, and care for, women whose children have been removed from their care? In this paper, we consider how women's experience of work with Pause might illuminate that critical debate, drawing on Fraser and Honneth's [21] discussions about recognition and redistribution.

In Honneth's theory (e.g., [22]), recognition encompasses three components-love, rights and solidarity - which are seen as the foundation for self-realization. His conceptualization of love can be understood as relating to care, and having one's physical and emotional needs recognized and met. The framing of rights, particularly in his later work, relates to reciprocal recognition of the other as a bearer of equal rights - the converse being legal and social exclusion within society. Finally, solidarity refers to recognition of strengths and social contributions, which Honneth frames as essential to the development of self-esteem. Honneth's work has been criticized for (over) emphasizing interpersonal relations at the expense of recognizing structural inequalities and relations of power. Perhaps most notably, Fraser's [23] feminist critique of Honneth's theory emphasized social justice and the need for redistribution to address the ways in which misrecognition contributes to the exploitation and institutionalized subordination of oppressed classes. She defines misrecognition as 'social subordination in the sense of being prevented from participating as a peer in social life' [23] (p. 24), explaining that:

'When [ ... ] institutionalized patterns of cultural value constitute some actors as inferior, excluded, wholly other or simply invisible, hence as less than full partners in social interaction, then we should speak of misrecognition and status subordination'. [23] (p. 24)

The historic absence of policy attention or service provision for mothers whose children are removed into care or adoption, and particularly those who experience repeat removals, can be recognized as socio-political misrecognition in Fraser's [23] terms. These women are subjected to 'stigma power' [1] (p. 249): multiply positioned as inferior and 'wholly other', or simply invisible. Their experience-as documented in the research discussed above-evokes Butler's [24] (p. 4) writing on power and recognition:

'I may feel that without some recognizability I cannot live. But I may also feel that the terms by which I am recognized make life unlivable.'

Honneth's later work engaged more explicitly with questions of power and social injustice, and he argued that recognition theory makes a particular contribution in addressing 'the place that justice has in our everyday praxis' [22] (p. 45). Houston [25] (p. 4) suggested that these arguments are especially relevant to welfare interventions, because 'critical theory helps to make [social work] interventions psychologically, culturally and politically sensitive'. Turney [26] (p. 152) similarly argued for the potential of recognition theory to enhance ethical thinking and practice in child and family social work. She highlighted Honneth's emphasis on reciprocity as key to emancipatory practice, recognizing the power differential between the woman/family and the professional, and helping to shift towards working in a relationship 'where each participant has something to offer and to receive'. In this context, the attention given to the value of fun activities within the Pause framework [18] is striking. As Fincham [27] (p. 10) notes, 'fun' is often trivialized and marginalized, even in discussions of wellbeing, because of classed associations 'with crassness or fecklessness [ ... ] with wasting time or not doing the important stuff'. Fincham's [27] (p. 33) research documents the multiple affordances of fun, including the potential to level out inequalities, because 'those that have fun together create the conditions for particular types of relationship'. In terms of Honneth's theory, fun could be seen as a crucial resource for reciprocal recognition and solidarity in relational work. Mutual engagement 
in fun activities might help to avoid a deficit-focused and stigmatizing 'way of seeing' [28] (p. 731), as part of an enabling practice that responds to inequalities of power by addressing social justice and 'establishing the misrecognized party as a full member of society, capable of participating on a par with other members' [23] (p. 26).

Aims

In this paper, we reflect on the potential of conceptualizing the work of Pause as concerned with recognition and redistribution. In doing so, several caveats are necessary. First, we must recognize that these concepts are not part of the Pause theory of change, nor are they anywhere articulated as part of the Pause approach. Our aim is to 'think with theory' [29] in order to reflect on the relevance of these concepts to the policy and practice of recurrence services, rather than to evaluate their implementation in Pause practice. Relatedly, we do not seek to comment here on the 'effectiveness' of Pause as an intervention in women's lives, or to summarize the findings of our evaluation, which have been reported elsewhere [17]. Rather, by drawing on interviews with women who worked with Pause, we aim to illuminate:

- How women's rights and needs can be obscured in the politicized intersection between their stigmatizing construction as mothers, as women, and as costs to society; and

- The relevance of concepts of recognition and redistribution-encompassing love, care (and fun); acknowledging human rights and political and economic injustice; and identifying strengths and social contributions - to understanding women's experiences of working with Pause and of change in their lives.

\section{Methods}

The analysis presented here is based on interviews conducted as part of a large multi-method evaluation of Pause, funded by the Department for Education in England. The overall evaluation methodology is not presented in detail here, but it was designed to integrate attention to process and outcome, in accordance with recent UK Medical Research Council (MRC)/National Institute for Health Research draft guidance on evaluating complex interventions [30]. The multi-method approach included qualitative longitudinal interviews with women who currently or previously worked with Pause; group and one-to-one interviews with Pause professionals (including members of the national team, managers and practitioners); interviews with local authority stakeholders in Pause and comparison areas; secondary analysis of Pause administrative data on women who work with the service; and secondary analysis of published local authority SSDA903 data on rates of infant care entry in Pause and matched comparison areas (see [17]). Ethics approval for the research was provided by the University of Sussex (Social Sciences and Arts Cluster Research Ethics Committee ER/JMB55/8).

Here, we focus on qualitative longitudinal interviews conducted with 49 women who were working with Pause at the time the evaluation began, in 2018. Participants were sampled from a mix of older and more recently established Pause practices, to represent different local authority and delivery characteristics, including a 'care leavers pilot' that targeted women aged 16 to 25 who had been in care during childhood and had one or more children in care or adoption. Participants were recruited to the evaluation as close as possible to the point of joining the program. The average age of these women was 28 years (range 19 to 39 years old); on average, they had 2.4 children (range one to five). None had children living with them at the time of recruitment to the study ${ }^{2}$. Women in the 'care leavers pilot' were younger (average 23 years old) and had fewer children (1.5 on average). 
Each woman was interviewed on up to four occasions over a 20 month period, usually twice face to face and twice by telephone ${ }^{3}$. With women's permission, interviews were digitally recorded and transcribed. Not all women were reachable at all time points and we exercised caution in pursuing women for interview, given their vulnerability and an ethical concern not to disrupt Pause work or put pressure on people who were in a dependent position as recipients of the service being evaluated. Hence, longitudinal data are subject to sample attrition ( $82 \%$ of the sample participated at Time $2,57 \%$ at Time 3, and 37\% at Time 4), although at least one post-intervention interview was conducted with 32 women ( $65 \%$ of the sample of 49 ). All women received a $£ 20$ gift voucher in thanks for participation in each interview.

All interviews were open ended, following a topic guide. This use of open methods aimed to provide opportunities for participants to 'disavow dominant perspectives' [31] (p. 114), with questioning designed to elicit women-centered accounts of their experiences. We used a life chart as a prompt early in the first interview (see [32], and adapted from previous research by [33]); by inviting participants to record significant people and biographical experiences across four domains (family; living situation; friends and other important people; and education, work or training), we aimed to ensure that we began by centering what women saw as important for us to understand about their lives. Beyond that, the primary focus of all the interviews was on women's experiences of the Pause intervention, including (as appropriate at each time point) processes of engagement with (or referral into) the program, experience of key features of the program including contraception, and the extent to which the program meets their perceived needs. The topics covered in the interview included information about current circumstances (including housing, relationships, employment, and contact with children) along with any other issues that women wished to discuss.

Ethics considerations were integral to the research, from evaluation design through data collection and analysis, and reporting (including in this paper). Throughout, we have sought to work with ethical hesitancy and reflexivity-including acknowledging our power as researchers in eliciting and presenting women's accounts of very difficult experiences-in our methodological and analytic decision making across the research process [34,35]. In particular, as is evident from the overview above, interviews were potentially highly sensitive, and were conducted with an emphasis on ensuring that women could talk freely about considerations that were important to them, and with care to avoid any pressure to participate or to discuss issues that they may have found upsetting or been reluctant to discuss. In the discussion that follows, women have been assigned pseudonyms and potentially identifiable case details have been withheld or amended in order to protect confidentiality.

Interviews were analyzed using a case-based longitudinal approach to examine key narratives and areas of interest (such as views of support and barriers and facilitators of change) as well as any issues arising during interviews. Within each case, an analytic summary was prepared for each time point; these were then combined into a whole case analysis which took account of change over time. Subsequently, cross-case analysis was conducted to examine patterns over the sample as a whole, taking account of any evidence of differences within and between subgroups in the sample. All interviews and analyses were conducted by the authors. The analysis presented here is focused on theory building, and so while we summarize broader patterns for the sample as a whole when appropriate, we draw in more detail on 20 emblematic examples, selected to illuminate the potential theorization of recognition and redistribution in relation to three key facets of work with women who have experienced a child's removal into care. First, we focus on recognition and redistribution in relation to women's rights to health and welfare; second, we consider recognition of women's motherhood and the distinctive nature of their loss; and we conclude by considering recognition in the everyday praxis of Pause, considering reciprocity, care, and respect.

3 In some cases, all interviews were face to face (for example, if women requested this); some were conducted predominantly over the phone (for example, if a woman was not available for a face-to-face arranged appointment on long-distance fieldwork, the rescheduled interview sometimes took place by phone). 


\section{Findings}

\subsection{Recognition and Redistribution in Rights to Health and Welfare}

'at the heart of [feminist] politics lie questions like, what do various groups of women really need, and whose interpretations of women's needs should be authoritative.' [36] (p. 104)

As might be expected in light of the research discussed above, women consistently gave accounts of accumulating and intersecting complex and chronic needs that were commonly unmet before they started working with Pause. These patterns were consistent with administrative monitoring data for the Pause population as a whole [17]. Their experiences highlight an ethical imperative for redistribution in order to ensure women's neglected rights and welfare entitlements.

Poverty and economic insecurity were widespread, and a critical source of vulnerability in women's lives. Only two women were not reliant on benefits at Time 1, and difficulties with debt, benefit eligibility and sanctions were very common. At baseline, one-third (16 women) were in receipt of basic welfare benefits (for example, Universal Credit) and 29 received benefits relating to health or disability. The precarity of life on benefits was a recurrent theme in women's interviews, and women who relied on Universal Credit frequently described being short of money for food or bills. One woman, Heather, was sanctioned when she prioritized supervised contact over a job center appointment and was left with $£ 130$ to live on for a month (instead of $£ 190$ as usual). She commented, 'I'd rather starve for a couple of days than not see my children.'

Another woman, Claire, had no source of income at the time of her first interview, after a disability related benefit was stopped and she was being transferred onto Universal Credit. She explained:

'They gave me no points even though I've got chronic [physical health condition] and got mental health issues as well. [ ... ] So, it's just like I've got a doctor's note still, so I've done the Universal Credit application and I'm going for an appointment on Thursday [... ] they're not going to give me any extra money but if I'm still getting signed off they can't say, my doctor says I'm not fit for work, so. [ ... I I've got an appointment on Thursday so hopefully they'll be able to tell me when I can get some money off them. [ ... I I mean because they're not even paying my rent.'

It is well established that both Personal Independence Payments (PIP) and Employment Support Allowance (ESA) systems (targeted benefits for people with chronic health problems or disabilities) disproportionately disadvantage people with mental health difficulties (e.g., [37]). Claire's narrative demonstrates her lived experience of misrecognition, including her struggle to understand why health problems that have been documented by a medical professional are not recognized and reflected in her welfare entitlements. Problems with (non-)payment of benefits could force women into decisions that could potentially exacerbate risk. This was starkly illustrated by two women in the care leavers pilot, who relied on boyfriends for money and/or accommodation because of non-payment of benefits. For example, asked how she managed financially, Louise said:

'That would be my boyfriend. He gets a decent amount of money from his job at [workplace] so with me staying with him until the flat's sorted [... ] he sort of provides for both of us food-wise and otherwise. He basically buys food and keeps us both stable and in good living condition. [ . . . Thank goodness I have a lovely boyfriend.'

Both women were relying on relatively new romantic partners-both relationships had lasted less than eight months at the time of interview, and by the time of our final follow up, one relationship had broken down permanently, and the other had restarted after a temporary break up.

Nearly 40 per cent (18 women) lived in insecure or unsuitable housing at Time 1, and of the 30 women who were in secure housing, seven had achieved this recently with support from Pause. Some women were still in homes where they had lived with their children, and while technically 'secure' in 
their housing, this could lead to problems with debt and rent arrears as a consequence of the 'bedroom tax' (see [10,38]).

Women in the care leavers pilot were more likely to live in accommodation that was insecure or unsuitable, although some had lived in these settings for considerable time. Leila had spent four years in supported lodging for people with disabilities; she shared facilities with two older men and explained:

'It's disgusting but I share a bathroom and a toilet and the people here, I don't want to judge, they're very filthy, they're nothing like me. [ ... I I had a really bad incident in the past which sort of broke me, like the guy showed his thing down there.'

Another participant in the care leavers pilot, Skye, was living in supported lodgings having previously been in emergency accommodation. At our final interview, she was soon going to turn 21 and was having to move again, possibly to a unit that she described as being 'where drunkies and chumps go when they're homeless'. She observed, 'Why have me in care since I was bloody 12 to tell me I'm going homeless? It doesn't make sense.' Skye attributed these difficulties to the stigma she carried through past experiences with the responsible manager in her local authority, who:

'used to be a social worker with my family and [...] and there was a bit of tension between me and that social worker and now she's the manager and cos she's the manager it's like they're not helping me [

... I She made it aware to everybody that I have to leave because I'm going to be turning 21.'

Skye's account reveals her status subordination, in Fraser's [23] terms, as her entitlement to support as a care leaver is rendered doubly precarious. This happens first by the ways in which she is seen (or experiences being seen) by the manager, and second by the time limits of 'corporate parenthood', which-in contrast to the policy rhetoric of 'acting as any good parent would' [39] (p. 8) - is in practice restricted by legal provisions for leaving care support. In these terms, her rhetorical question 'Why have me in care?' and observation that 'it doesn't make sense' can be understood as a reflection on her experience of policy and professional misrecognition, obscuring her needs and rights for safe housing and support through the transition into independent living.

Across the sample, women emphasized the importance of support from Pause practitioners to address economic and housing insecurity, both in addressing urgent needs-for example, securing safe accommodation in the context of domestic violence-as well as seeking longer-term solutions, by advocating for housing or supporting PIP applications and appeals. Women highlighted the role of their practitioners in recognizing and advocating for their rights, and the distinctive importance of this in a context where they commonly had multiple service involvement and complex, intersecting needs. For example, over the course of our research, Claire-who had chronic health problems, as noted above-spoke of her Pause practitioner's efforts to find her secure housing and enable her to move out of a temporary hostel that she described as like a 'prison'. Originally, she had been told the hostel placement would only be for three months, but by our second interview she had already been living there for six months, with no prospect of a move:

Yeah, but now they've also said [I will be here] six months, and [Pause practitioner]'s like, "Well, she has been there six months. Do you want to look up her actual name?" So yeah, [practioner]'s just trying to dig her heels in.

By the time of her third interview, just under a year later, Claire was settled in a flat; now living near her children's kinship carer, she had been able to see them on a recent birthday. Claire explained that after many years and several changes of housing worker, she had had little hope of ever securing a stable home:

I was literally thinking [ ... I I don't think this is ever going to fucking happen [ .. ] At that point, last time I spoke to you, they still hadn't agreed. But [practitioner] was like a dog with a bone. 
She would not let it go. She was, like, she's been waiting 14 years... She's been on the list since she was 16, so even though you took her off [the housing list] without her knowledge or her say so [... ] [Practitioner] wouldn't let it go, and I'm so glad because literally I've got a really nice flat in [neighbourhood], it's massive.

As illustrated by Claire quoting her practitioner asking, 'do you want to look up her actual name?', women's accounts often linked such change to their Pause practitioner's distinctive recognition of them as people with needs and rights. The experience of recognition of economic rights is illustrated through interviews over time with Hannah, who lived with significant mental health problems, related to a history of significant trauma which included childhood abuse, domestic violence, and drug addiction. When she started working with Pause, she was surviving on basic benefit entitlements. In her first interview, she gave a detailed account (edited here) of her struggle to manage on Universal Credit, and the role of her practitioner in enabling her welfare rights:

It was hard before but they recently sorted my benefit out for me, I was on really bad money before for quite a while. [ ... I I'm on Universal Credit, I'm now on the ESA component which is new style ESA and I also claim carer's allowance for [relative] so my financial situation at the moment, I'm managing at the moment whereas before it was really hard before I sorted out the ESA part of my benefit. It was just Universal Credit. [ ... ] And that was 170 to 190 on average a month. I know, it was really like is this for real? I couldn't believe it was right but it's 'cause they didn't realize I was sick at that point, like, had mental health problems and after a while dealing with me they kind of clocked on and was like, you need to apply for this part of the benefit so yeah. That's sorted now, yeah. [... ] [Pause practitioner] did give me a lot of help with that to be honest. [ . . . Especially if you're already depressed and whatever you can't be bothered, you think, I'll just leave it unless you've got someone actually to help you to fill them forms up.

Hannah's story highlights how her mental health needs make it more difficult to navigate a complex benefits system, and so to secure her entitlements. She had also accumulated significant debt, including as a result of benefit underpayment. Her experience shows the role of her practitioner, not simply in signposting, but in recognizing her intersectional needs and rights. Alongside a practical focus on finances, the practitioner supported Hannah in accessing specialist therapy, and this combination of support had helped her to manage her mental health, address domestic violence and maintain recovery from addiction. At the time of her first interview, Hannah had also applied for PIP with the support of her Pause practitioner but had been unsuccessful. By her final post-intervention interview, she had applied again, and subsequently appealed. She told us, 'I fought against PIP and I won', and explained:

They turned me down, because I had tried to do it before and I ended up feeling worse and getting told no and feeling really down [ ... ] and then I got to a point where I felt like no, I am appealing it, I am unwell, I'm not scamming the system, I'm not well, my doctors agree with me so I'm entitled to it. And I fought and they said, "Alright, you can have it."

Hannah's example indicates how her recognition of economic injustice-'I'm not scamming' - helped her find the strength to fight for her entitlements. Following her successful appeal, her payments were backdated by two years. Supported by a relative, who 'helped me spend it on the right things, things that are going to last', she was making improvements to her council flat, including replacing a cooker that had long had only one functioning ring. As reflected in her award of PIP, Hannah lives with chronic mental health problems that at the time of our final interview had recently been exacerbated after a traumatic event. She sought the support of Pause (with whom she remained in touch) and was securing a new referral for further therapy-again, reflecting her recognition that she needed (and was entitled to have) this specialist health care. Considered as a whole, her account reveals the political functions of recognition-in terms of her entitlements to state welfare, and to the quotidian securities that affords-as when Butler [24] (p. 224) writes of 'the moment in which a subject [... ] asserts a right or entitlement to a livable life when no such prior authorization exists'. 
More than three-quarters of women in the sample (39/49) described significant mental health issues, often related to histories of complex and chronic trauma. Most commonly, women reported anxiety and depression, but several reported suicide attempts and/or significant psychiatric diagnoses including schizophrenia or borderline personality disorder. Some also described multiple and shifting diagnoses over the course of the longitudinal study, bringing to mind Dalgleish and colleagues' [40] (p. 186) arguments for transdiagnostic approaches in mental health provision that can 'better address the heterogeneity and comorbidity that is the modal presentation in real-world services'.

Relatedly, almost half the sample (20/49) reported significant drug or alcohol problems, and were either currently in recovery or still dealing with alcohol or substance use. In some cases, women described self-medicating because of difficulty in accessing services. For example, Jade was on a waiting list for counselling, having made multiple suicide attempts. She explained that she was having difficulties with the referral because she continued to use cannabis:

I don't get any sleep, so when I haven't got it I don't sleep, but when I do have it I can get some sleep. So we've contacted the mental health team. They're saying, "Oh no, you've got to be abstinent from it for six months." I'm like, "No, that's not going to help me," [ . . ] [Pause practitioner]'s saying, "No, that's not realistic. She's using this as a coping mechanism till she's got support there." [ ... ] I don't want to have to smoke, but it is the only thing that is helping me right now. They won't give me sleeping tablets because I'll overdose on them. I can't take antidepressants because I'll overdose.

Jade's experience shows how professional misrecognition of the connection between her mental health and substance use was a barrier to her needs (and rights to health) being met. Her use of 'we' to refer to herself and the practitioner illustrates something else that was highlighted by numerous women and practitioners: how important it was that her practitioner did recognize her experience, and used her professional power to act in solidarity with her, fighting for her access to health care to ensure her needs are met.

Recognition of equal rights is a cornerstone of Honneth's [22] understanding of reciprocal recognition, and there are inevitable questions about how this emphasis fits (or not) with the contraceptive conditionality of the Pause model. What are the implications for power, rights and equality in the relationship between a woman and her practitioner if that relationship (and the support it enables) is subject to her accepting the program's contraceptive requirement? The Pause framework [18] (p. 14) sets out an expectation that 'there is plenty of time for practitioners to talk to a woman about contraception, as well as linking in with her local sexual health service to get expert medical advice and services'. There are two key implications here. First, that there should be 'plenty of time' for women to make a decision in the context of conditionality, and second, that contraceptive conditionality goes alongside women's engagement with sexual health services, which can be seen as supportive of her rights to health.

Our analysis indicated that women were being supported by Pause in relation to reproductive and sexual health, for example, being encouraged and accompanied to cervical smear tests. Just over half of those interviewed said they had already been using some form of contraception (usually a long-acting reversible method) before they started working with Pause, and the majority of women in our sample expressed no concerns about contraception. Several women emphasized their Pause practitioner's care to ensure they did not feel pressured into uptake of long-acting reversible contraception (LARC), such as Megan who described her practitioner as 'very soft and gentle about it'. However, as discussed in detail the main evaluation report [17], one-fifth of women in the main interview sample raised some concerns about contraception, often relating to their experience of side effects. Particularly relevant to questions of reciprocity and equality in recognition theory, eight of the 49 women that we interviewed raised questions about the ethics of conditionality, in terms of lack of choice or control. For example, Bryony explained that despite feeling 'a little bit funny about the whole contraception thing', she decided that it was 'something that had to be done'. Similarly, Zoe commented that she understood the value of using contraception, but nonetheless, 'I think it should be [women's] choice. We get a choice 
but not a choice as such if you know what I mean'. Such comments reflect women's awareness of their dependent position, a dependency that arises from the importance they attached to other aspects of Pause support in the context of a wider welfare system neglect of their rights and needs. Hence, in the context of Honneth's [22] emphasis on equal rights, even if most women do not express concerns, the tensions between much valued support and bodily control can be seen as paradoxical to a praxis of reciprocal recognition.

\subsection{Recognizing Motherhood}

'If we stay with the sense of loss, are we left feeling only passive and powerless, as some fear? Or are we, rather, returned to a sense of human vulnerability, to our collective responsibility for the physical lives of one another?'. [24] (p. 23)

For women who work with Pause, their possible subjectivities as mothers have been shaped by the regulatory power of the state, in ways that constrain their possibilities for grief and their recognition as mothers $[10,11]$. To highlight this impact is not to question the validity of complex prior decisions about child placement or permanence (which are in any case beyond the scope of the research), but it raises a question about the extent to which a woman who is not able to retain custody of her child is allowed to be recognized as a mother. Pause documentation, including the Pause framework [18], consistently refers to women rather than mothers, and-particularly in the context of contraceptive conditionality - this could be seen to raise a question about the ways in which women's motherhood is recognized through the program. The focus of the program is not on working with women's parenting capacity, with the aim of securing children's return from care. Instead, it is focused on work with women's own needs and priorities, based on 'genuine interest in her life and a change from how other services may have worked with her' [18] (p. 27). The framework also highlights the need for practice to recognize that women's potential stories of themselves as mothers have often been "'problem saturated"' [18] (p. 18). As such, the program's focus on the woman need not obscure recognition of the mother, but rather can be seen as intended to enable alternative narratives: recognizing women's motherhood without reducing them to a problem-saturated and stigmatized maternal identity.

The women we spoke to foregrounded their identities as mothers, and our interview fieldnotes often documented children's visible presence in their quotidian lives-for example, with names tattooed on forearms, photographs displayed on walls and mantelpieces, and pictures visible on the lockscreens of smartphones. Many also talked of thinking, and worrying, about their children's care and wellbeing. Kimberley highlighted this, and her comments also illustrated that she felt Pause recognized her concerns:

They've started to be like helping me out a bit more with my kids wise because I worry about my kids

24/7. I worry about what they're eating, what they're doing, anything. I keep telling Pause and that they're like, well we can't do nothing yet, but if it carries on and you still don't feel happy and what's the word, satisfied the way that your children are being treated we'll go somewhere.

Women's accounts of Pause emphasized the ways in which practitioners engaged with their identities as mothers, and this was often contrasted with other forms of professional misrecognition of their motherhood. For example, in one Pause practice area, two women with adopted children described how Pause had helped them stop the adoption team referring to them as 'tummy mummies'. As Maddie said:

I'd understand if I was a surrogate mother called a Tummy Mummy, because that's all I am. But [... ] he's my child, so why are they calling me a Tummy Mummy? That doesn't seem right to me.

Her comments evoke Fraser's [23] arguments about the status subordination that goes with misrecognition, and Broadhurst and Mason's [10] observations about birth mothers' disenfranchised grief. By contrast, several women discussed the ways in which Pause practitioners recognized and 
responded to the ongoing impact of their loss. For example, Leanne started working with Pause two months before an adoption order was made, a traumatic period when she still had twice weekly contact 'because they hadn't found adopters for the children':

[Practitioner] would meet me at the contact afterwards, once I was finished there she would be outside waiting, I could guarantee it, ready to take me for a coffee and she was a shoulder to cry on, because the children would go and I would just break because my daughter would be sobbing and hanging on and, "Take me home, take me home." And my son was like, "Mummy, I want you, I want you." And [practitioner] was like literally holding me like through all of it.

At the point of our Time 1 interview, Leanne reported that her Pause practitioner was now supporting her through problems with letterbox contact, noting that the practitioner was 'endlessly chasing the adoption social worker' to ensure she would be able to write to her children for Christmas.

Women consistently highlighted ways in which work with Pause could help with the ongoing reconfiguration of their loss, establishing identities and supporting their practices as mothers at a distance. This can be seen as a form of recognition, enabling alternative narratives of ongoing motherhood that allowed women's expertise in their children. For example, Leila, whose children were adopted, spoke with pride about choosing cards for letterbox contact:

[Practitioner] got these, I chose them, I told her what kind of cards they love, [daughter] likes, she likes sparkle and stuff. You know at first you don't really know your kids and then you get better with them.

Alicia had regular unsupervised contact with her child in foster care, and aspirations that they would in future be able to return home. In her final (Time 4) interview, no longer working with Pause, she demonstrated her care and understanding as a mother in a detailed account of her concerns about her child's wellbeing and happiness in the foster placement, documenting a number of specific issues including the following:

I think [child] is getting bullied, [child] keeps talking about how [they] don't like [their] colour. I'm not being funny, they have taken a black kid basically and stuck [them] in the whitest place ever with a fully white family that doesn't know how to maintain [their] skin, doesn't know how to maintain [their] hair.

As was the case for Kimberley, Alicia's account makes clear that the lack of professional recognition of her worries added significantly to her concern about the situation. She had not been able to make contact with her child's social worker, despite several attempts and, unable to talk to any professionals about her concerns, she commented that 'I'm definitely nearly on the complaint making base'. She explained that her confidence to raise a complaint was linked to her experience of participating in training for social workers whilst she was working with Pause. She explained, 'I got a platform to speak out [ ... ] to say, "How can we get this better for next time?".

Arguably, Alicia's work with Pause helped her recognize herself as someone who has the power to speak out, entitled to be heard as a mother of a child in care. But her account of her concerns, alongside the lack of response from the social worker, simultaneously reveals the lack of power and 'voice' inherent in her positioning. In her first interview, she spoke about the stigma she faced as a care-experienced mother, and commented:

But I can kind of tell if people want to get to know me or if they've read about me, both; they look at me completely different when I start speaking and I'm like, "So you judged me on reading about me and you haven't got to know me."

If professional narratives of women are 'problem-saturated' (to paraphrase the Pause framework), this is likely to obscure recognition of them as potentially knowledgeable or caring in their motherhood. While of course we only have Alicia's account of the situation, her experience suggests that the failure 
of her child's social worker to respond to her concerns as a mother could have an adverse impact on their professional understanding of her child's needs and wellbeing.

Communication between birth mothers and the professionals involved with their children is inevitably complex, but our analysis suggests that this may be less difficult when women are recognized and supported in managing motherhood at a distance. For example, across all her interviews, Jess discussed ongoing issues with contact with her children who live in foster care. At Time 2, she expressed concerns about a contact session that had been arranged while her children were in school:

I was meant to have it half-term week, they booked it for when the kids were at school and I didn't want to take them out of school, but I didn't want them to feel as if I was rejecting my contact because I wasn't, it was the fact that they're at school and their education is more important. And [Pause staff] did actually sort it out for me, but if I didn't have them I don't know what would have happened, would I be in the same boat or not. I have put in a complaint to Social Services anyway regarding that, because I feel as if I was being sort of penalized or isolated and stuff like that.

Twenty years ago, Cleaver's [41] research criticized the tendency for school-aged children to be given contact arrangements that interrupt school; Jess's account suggests that little has changed. But, whilst her Pause practice recognized and responded to her concern, and 'did actually sort it out for me', her explanation indicates a very different interpretation of her actions from social services-that she was 'rejecting' contact and was being 'penalized or isolated'. Jess's rhetorical question-'would I be in the same boat' without the professional advocacy of Pause?-speaks to the lasting effects of stigmatizing misrecognition for women, and the potential impact on their children's wellbeing [42].

Like Alicia, Jess's interviews over time reveal her growing confidence and empowerment in arguing for her rights in her relationship with her children. By her final (post-intervention) interview, she said she had got the social work team manager 'on my side', and secured agreement for increased time with her children. She had also discovered that she should have been permitted unsupervised contact—which had not been done—and had taken this up with the Ombudsman ${ }^{4}$. She explained:

I've always said I will never give up on my children. And whatever, sort of ... if they push me down, or whatever, I still pick myself up and still go ahead with it, because I'm a mother, you know?'.

Maintaining identities as mothers also appeared important for women in managing hopes for potential future children. As is well documented in Broadhurst and colleagues' (e.g., [8]) CAFCASS analysis, once a woman has been through proceedings with a child, she has a significantly increased risk of further children being removed from her care. Some women explicitly acknowledged the risk of further social care intervention should they have further children, such as Emily who commented in her final interview:

'because of having to have the rod [implant], I wouldn't have had that rod and I'd have probably been pregnant or fighting for a kid again'.

Several women discussed their existing identity as mothers in relation to their decision-making about contraception, and their plans for having children in future. For example, Leila reflected on her decision to use long acting reversible contraception:

This is how we decided, we decided this, right, it took long but me and [partner] decided not to have kids no more because we don't want our third kid to go through the pain that [children] went through, taken away from their parents. So we decided ... we was talking about the future, like not now, but we decided once we settle down we'd like to have kids but right now focus on getting out of here and settling down and focusing on my skills but maybe soon, not now maybe three years, two years later we'll have a kid but not now. 
Almost all the women we interviewed had chosen to continue using contraception after they had finished working with Pause. Arguably—as illustrated by the comments of Leila above-when women are recognized and supported to maintain their identities as mothers to existing children, it may empower their decision-making about whether, and when, to have further children.

\subsection{Recognition as Praxis: Reciprocity, Care, Respect and Fun}

'recognition may not consist in mere words or symbolic expressions, but must be accompanied by actions that confirm these promises'. [22] (p. 92)

The women we interviewed all had extensive experience of multiple different agencies being involved in their lives, and as detailed above this was often experienced in ways that could be understood as misrecognition, both frustrating and stigmatizing. By contrast, women consistently described very different relationships with their Pause practitioners. Their accounts correspond with the aspirations of the Pause framework [18] (p. 14), which states that women who work with Pause can expect 'a relationship where women are valued and respected for who they are as women-not simply in relation to their maternal identity or presenting issues'. In our main evaluation, Pause staff also emphasized that a holistic emphasis on seeing the whole woman was a distinctive feature of the work, and similar comments were made in interviews conducted in local authorities that provided other recurrence services [17].

In line with Honneth's (e.g., [22]) conceptualization of solidarity, women's accounts of their practitioners highlighted recognition of their strengths (as well as their needs). Several also used the language of 'family', 'love' and 'friendship' to describe their relationship with Pause or with their practitioner. For example, Jasmin responded to the 'family' section on the life chart by saying:

Family: to me my family is Pause at the moment, they're there where my family hasn't been, so I don't know if I can put Pause but it's how I would say that because they're my support network and they're the closest I've got, I've got friends of course but then it's mainly family and I don't have my own family. [ ... I I don't have a family because they're not supportive; they weren't aware [child] had gone into foster care, they've never been to see [child]. So in terms like that when I need support, I don't have family, whereas Pause ... [interviewer: they've been more supportive?] I think Pause is my family.

She explained this in terms of Pause providing the kind of practical and emotional support that she would expect (but did not receive) from family, but also because, 'with Pause I see it differently; not [because] I've worked with Pause longer, but it's how they've worked with me and how they've understood me.' Other women gave similar accounts of relationship-based practice that was person centered, and very different to other experiences with professionals. For example, Susie explained:

When I go into a meeting with professionals and stuff, I feel like when I am in social services and other agencies I have had to work with, I feel like just another number on their books, you know on their caseload. But with Pause it is completely different because you have that time to build a relationship up with them and you become comfortable around them. Like, you see them a lot more than you would anyone else. Like, if they are passing they will just pop in like or if they are having days out as a group they will just call me, 'Susie, what are you doing today, do you want picking up? Do you want to go to the cinema?'

The practitioner's investment of time in the relationship is key to the sense of care in Susie's narrative-spending enough time together to become comfortable together, and to have time for spontaneity and fun, whether just to 'pop in' or to engage in leisure activities such as a trip to the cinema. Also apparent, in her interviews over time, was Susie's confidence that this is a reciprocal relationship, and she described her practitioner's shared enjoyment of these activities. In her Time 2 interview she talked through the photobook that her practitioner had made for her 'graduation' from 
Pause after 18 months; showing the interviewer a photo of somewhere they used to visit regularly for days out together, she said 'We often used to have [place name] days, it was one of our things we liked'. Her use of collective pronouns-'our things we liked' - to describe their shared enjoyment echoes Jade's (above-quoted) account, in a very different context, of collective action (in that case, fighting alongside her practitioner to access mental health support).

Susie's account of her photobook also evokes Fincham's [27] observations about fun as a resource for positive reminiscence, which in turn enables perspective on the present day, and so fuels a sense of who one is. Thus, fun activities could be seen to contribute to the reconfiguration of self proposed in the Pause theory of change. Building positive memories may also have distinctive value for women who have experienced multiple trauma in their lives; Fincham [27] discusses fun as a means of being 'carefree', forgetting worries and responsibilities. In her first interview, Eva discussed the ways in which group activities made it possible to 'switch off':

We've been to [theme park] as a group which was a really good day out, and I got to meet most of the girls that came, some didn't. And we've been to [town] and had fish and chips and ice cream and stuff. And they do things to help you switch off from thinking about what's going on with social services, what's going on with the children, all that sort of stuff, you can switch off from it for a bit and it's all people that understand because they've all been through it and everything.

Arguably, reconfiguration of self may also be enabled by the trangressive nature of fun activities - transgressive, in that these activities allow women to occupy a different, de-stigmatized, subject position. Fincham [27] (p. 41) writes:

'Transgression need not be some sort of grand statement; it may simply mean not really doing what you are supposed to or what you normally do'.

Examples given in our interviews included group sessions such as crafts, cooking, bowling, choirs, and hair and beauty skills, as well as one-to-one activities with women and their practitioners, such as going for coffee or for a meal. Women's accounts demonstrate that these activities provide relational space that felt very different to their previous professional encounters. This can also be understood with reference to the social pedagogic concept of the common third (e.g., [43]), whereby mutual engagement in an activity in which all parties are invested can help to flatten hierarchies and create a new form of relational space. Our analysis suggests that the joint nature of these activities is particularly important, reinforcing solidarity and reciprocal recognition. This was explained by Maya who described her relationship with her practitioner as like that of a friend or an older sister:

I don't see her like she's one of the, like, she's a staff member, it's more like she's my older sister and I'm just going to rant at my elder sister because I've had a shit day or something. We've done loads of stuff, we've been to the cinema, we've been and had pedicures done. Like, they've helped me build on my confidence so much even as a woman. Like before, I would never have had the guts to go and have someone playing with my feet and doing my toenails.

The examples Maya gives-cinema and pedicures-evoke fun and friendship (the latter, particularly female friendship) rather than professional intervention. But her account also reveals how her practitioner scaffolds her social inclusion, building her confidence in two distinct ways. First, in her reflection on the pedicure, Maya shows her ability to engage in previously unimagined activities, revealing a changing sense of her right to occupy public spaces, and evoking Fraser's [23] (p. 26) comments about establishing rights as 'a full member of society, capable of participating on a par with other members'. Second, and perhaps most fundamentally, she is able to trust that someone cares to listen when she has had a 'shit day'. In this context, fun joint activities can be understood with reference to Honneth's [22] framing of recognition in terms of love, rights and solidarity.

Turney [26] wrote about the value of reciprocity in recognizing and addressing the inherent power differential in relationships with professionals for vulnerable women and families. For Maya, her sense 
of equality in her relationship with her practitioner was shaped by her knowledge that they were 'both new', as she explained:

I was [Pause practitioner's] first client so we were both new to the situation, both just as nervous, and I don't know, obviously, being open with [practitioner] and being able to go to [practitioner] and talk to [practitioner] about whatever's bugging me at that time, it made it ten times easier. If she didn't love her job and the staff at Pause didn't love their jobs, you'd be able to see it and that's the one thing that I have to give the women at Pause, you can tell that they adore their jobs, you can tell that they go home at night feeling like they've done something with their day whereas some, there are some people in that industry, they go home and they just cry themselves to sleep because they feel so bad.

Her narrative brings to mind Butler's [24] (p. 149) comment that 'it is in a moment of vulnerability that recognition becomes possible'. Through a reciprocal relationship, Maya is able to recognize her practitioner's vulnerability-her nervousness in a new role and the emotional intensity of her work-and this reinforces her sense of mutual connection, enabling her trust and confidence. Maya's account was exceptional in reflecting so thoughtfully on the experience and potential vulnerability of Pause practitioners, but the sense of reciprocal care that she describes was common in the sample.

Women's reflections on their experiences over time prompt a question about the implications of the temporal boundaries of the Pause relationship for conceptualizing praxis in terms of recognition. Targeted interventions are commonly time-limited, and our wider evaluation concluded that the 18 month duration of the program was crucial in giving women the time they need to establish foundations for change in their lives [17]. But what does it mean when an intervention that feels like 'family', in Jasmin's words, comes to an end? Especially in the context of women's prior experiences of traumatic loss, might a fixed time boundary undermine a sense of solidarity and mutual care between women and their practitioners? Particularly in midpoint interviews, several women expressed anxieties about the end of the intervention, and it was clear that endings could be destabilizing for some. The evaluation also showed the importance of flexible and gradual transitions-not only because of the significance of women's relationships with Pause, but because life continues to be complex for many women post-intervention due to factors outside the scope of the intervention (see [17] for a detailed discussion). Over the course of our research, Pause have been developing a 'Next Steps' flexible post-intervention support, and women spoke of the importance of this-not only as a 'safety net' as they navigated complex lives after 'graduating' from Pause, but as a way of enabling them to remain part of the 'Pause family'.

\section{Discussion and Conclusions}

The research discussed here was conducted in a societal context where austerity policies have framed severe cuts to the welfare state in England. Funds available to councils to fund local services have fallen by an average of $24 \%$ per person in the last decade, with the largest cuts in the most deprived urban local authorities [44]; these policies have led to the erosion of support for vulnerable families, and corresponding growth in child protection interventions and placements [3,4]. These changes to the welfare state have been justified, in policy and in media, through a political economy of stigma, which marks some women in particular as 'other', intentionally responsible for their own and society's problems $[1,5,6,45]$. Against this context, it is perhaps unsurprising that women we interviewed were so appreciative of a de-stigmatizing experience of relational work, which could be understood in terms of reparative attachment possibilities, but was distinctively characterized by care, solidarity, and respect-and the distinctive affordances of fun.

Women's accounts of their experiences with Pause indicate the relevance of Honneth's [22] theory of recognition as a resource for (re)conceptualizing support for people who are both highly vulnerable and exceptionally stigmatized. In accordance with previous research (e.g., [10-12]), the findings highlight the ways in which women's lives have been inextricably shaped by stigma and trauma, 
and show that their complex circumstances and support needs were commonly misrecognized or unaddressed at the outset of the intervention.

Poverty was a constant presence in women's narratives, contributing to their precarity and the intersecting and cumulative risks that they had navigated through their lives. The feminization of poverty (e.g., [30]) was evident, for example, in the effects of the bedroom tax after children had been removed from women's care. Equally, the research shows how the consequences of trauma-including the loss of a child into care or adoption-could make it harder for women to manage the bureaucratic complexities of targeted benefit applications (such as Personal Independence Payments). The Pause theory of change sets out stabilization as a fundamental component of the work, and our analysis shows that key facets of stabilization, such as economic and housing security, were enabled by Pause practitioners' recognition and solidarity with women as people - with an 'actual name' (as Claire said, quoting her practitioner). This was demonstrated in accounts of practitioners' tenacity in pursuing women's welfare rights-arguing for redistribution and social justice in Fraser's [23] terms, in accessing benefit entitlements, rights to secure housing and to health care. Women's interviews over time also revealed that-while they very often continued to live with significant challenges-they could be empowered (including beyond the end of the intervention), by recognizing themselves as being entitled to health and welfare provision. It appears that practitioners' solidarity could shift women's sense of internalized stigma-enabling new understandings of themselves as worthy of support (cf. [12]). Their recognition that the right to a livable life is not 'scamming', to use Hannah's term, evokes Butler's [39] (p. 24) observation that 'vulnerability can be a way of being exposed and agentic at the same time'.

Fraser's [23] work on redistribution and Butler's [24,46] writing about vulnerability and power provide an important critical resource for thinking through the distinctively gendered experience of misrecognition for women whose motherhood has been reconfigured by the state. The need for the praxis of recognition to engage specifically with gendered inequalities can be seen in the tensions associated with contraceptive conditionality. In our research, even though most women did not express concerns about the Pause contraceptive requirement, the governance of reproduction was evidently uncomfortable for a significant minority within the sample. Even when they appreciated the intent of the requirement, this tension could be experienced as paradoxical in an approach that otherwise emphasized reciprocity in recognition. Conversely, enabling (rather than requiring) women's access to information and advice in relation to long-acting reversible methods of contraception could be seen as consistent with Fraser's [23] arguments about social justice, if 'viewed as a means of promoting intimate citizenship, by facilitating more informed exercise of the rights framing intimate life [ ... ] empowering some parents through a potential enhancing of their reproductive and relational autonomy' [19] (p. 561).

Women's narratives demonstrated the manifold ways in which shame lived on the eyelids of the professionals they encountered, in ways that could 'reproduce or naturalize existing stigmatizing tendencies' [1] (p. 213). This stigmatization was perhaps most profound in their accounts of their motherhood, and evidence of professional misrecognition of women's love and concerns for their children's welfare poses an important challenge for policy and practice. To raise this issue is not to question whether past placement and permanency decisions had been appropriate-that is clearly beyond the scope of our work. As discussed in the main evaluation report, most women understood, and often spoke at length, about the ways in which difficulties such as drug use, mental health problems and domestic violence had affected their capacity to provide care for their children, or even to maintain contact [17]. But the examples given here show that, if professionals only view their motherhood through a 'problem-saturated' lens, this amounts to a stigmatizing misrecognition. Moreover, a failure to acknowledge women's continuing concern for their children-however complicated that might be-means professionals may fail to benefit from women's knowledge and insights about their children. Our analysis indicates that, in some cases, this could risk adverse implications for children's wellbeing.

Our research suggests that women could (and would want to) help professionals act in children's best interests, for example, in their experience of life with their foster carers, or in managing contact so it does not disrupt school attendance. Women's accounts of Pause emphasized the ways in which 
practitioners engaged with their identities as mothers: practitioners' recognition of women's enduring motherhood entailed acknowledging loss, vulnerability and ongoing connections. The research indicates that - as in the examples given in this paper-this recognition of women's motherhood could support them to manage safe and meaningful involvement in children's lives, as appropriate across diverse forms of placement. This finding is consistent with an international literature on contact, which concludes that supporting birth parents' safe and meaningful involvement is likely to have concomitant benefits for children's wellbeing, through childhood and beyond [42]. But equally, recognition of women's motherhood can be understood as a matter of social justice, in terms of rights to family life for children (and their biological mothers), as set out, for example, in Article 8 of the European Convention on Human Rights [47].

In conclusion, it is worth reiterating that this paper has not attempted to summarize evaluation findings about the efficacy of Pause support, which have been reported elsewhere, as have recommendations for the future development of the program [17]. The overall evaluation compared rates of infant care entry in local authorities with Pause practices and matched comparators with no known service for women at risk of recurrent child removals (and reported a significant positive effect over time, see [17]), but the qualitative longitudinal component of the design did not include a comparative element. Rather, it was designed to illuminate the complexity of women's experiences during and beyond their time working intensively with Pause. It is also important to recognize that we did not compare outcomes between Pause and other services that work with women who have experienced child removal, and cannot draw any conclusions about the model's relative efficacy in comparison to other services. As discussed elsewhere in this special issue, this is a rapidly developing field of provision, and other services share many of the same core values, for example in relation to the emphasis on trust in the relationship between woman and practitioner, and report promising evidence of positive change in women's lives (see [14], this issue). To understand whether the facets of recognition discussed here are crucial ingredients for interventions that aim to reduce risk of child removals, or to extrapolate from this study to other national contexts, would require further research.

Nevertheless, our analysis clearly indicates that Honneth's recognition theory has value for conceptualizing support for a group of women who have been amongst the most stigmatized and neglected in society. Overall, women's accounts of their experiences with Pause highlighted the ways in which recognition was embedded in praxis-through reciprocity, care, respect and fun. Women consistently described the relationship with their Pause practitioner as a different kind of relationship, and spoke in terms of reciprocal care, solidarity and respect that was nonetheless rooted in a trauma-informed attention to their needs and the complexity of their identities as mothers. The facets of Pause practice that correspond to the praxis of 'recognition' (in Honneth's terms) appear to help women navigate the ongoing challenges of complex lives shaped by chronic disadvantage and discrimination.

Understanding the experience and impacts of stigma for women in the study makes it possible to see why recognition matters-and why the way that women felt they were seen by Pause was so significant to them. Their accounts reveal the presence of stigma through encounters with multiple professionals in their lives, reading about them instead of getting to know them, as Alicia said. By contrast, when women and Pause practitioners sing together, share food, watch a film or have their toenails painted, their reciprocal experience of engagement establishes the 'network of care and solidarity' necessary to address the social and political injuries caused by stigma [1] (p. 29). These were also the features of Pause practice that women valued most highly and that they felt made most difference in their lives, creating possibilities for women to occupy a different, de-stigmatized subject position and recognizing their rights and needs without reducing them to their difficulties. Other authors have written about the potential of recognition theory to inform ethical praxis in social work (e.g., $[25,26])$ and our research reinforces and extends their conclusions. In supporting women judged to be at risk of repeat removals of children into care or adoption, the everyday praxis of recognition - through care, solidarity, reciprocal respect and fun-can be seen as a practice of collective 
political resistance in Butler's [46] terms, challenging the socio-political marginalization of women's lives and enabling their rights to participate fully in society.

Author Contributions: Conceptualization, J.B.; methodology, J.B. and B.W.; formal analysis, J.B. and B.W.; investigation, J.B. and B.W.; data curation, J.B. and B.W.; writing-original draft preparation, J.B.; writing-review and editing, B.W.; funding acquisition, J.B. All authors have read and agreed to the published version of the manuscript.

Funding: This research was funded by the Department for Education, within Round 2 of the Innovation Programme for Social Care (RR1042). The views expressed in this paper are those of the authors and do not necessarily reflect those of the Department for Education (DfE).

Acknowledgments: The research discussed here formed part of a larger study, which involved Susannah Bowyer, Rebecca Godar, Chris Hale, James Kearney, Oli Preston, and Julie Wilkinson. All those named have made a contribution to our thinking through discussions over the course of the project, and we are grateful for their wisdom and support. We are also grateful to support from colleagues within DfE, at Opcit (the evaluation coordinators), and to Pause staff who facilitated our research. Above all, we offer heartfelt thanks to the women we interviewed, who gave so generously in sharing their experiences.

Conflicts of Interest: The authors declare no conflict of interest. Neither Pause nor the funders had any role in interpretation of data presented here, in the writing of the manuscript, or in the decision to publish these analyses.

\section{References}

1. Tyler, I. Stigma: The Machinery of Inequality; Zed Books: London, UK, 2020.

2. Broadhurst, K.; Alrouh, B.; Mason, C.; Ward, H.; Holmes, L.; Ryan, M.; Bowyer, S. Born into Care Newborns in Care Proceedings in England; Final Report; Nuffield Foundation: London, UK, 2020.

3. Bilson, A.; Bywaters, P. Born into care. Evidence of a failed state. Child. Youth Serv. Rev. 2020, 105164. [CrossRef]

4. Bywaters, P.; Brady, G.; Bunting, L.; Daniel, B.; Featherstone, B.; Jones, C.; Morris, K.; Scourfield, J.; Sparks, T.; Webb, C. Inequalities in English child protection practice under austerity: A universal challenge? Child Fam. Soc. Work 2018, 23, 53-61. [CrossRef]

5. Featherstone, B.; Gupta, A.; Morris, K.M.; Warner, J. Let's stop feeding the risk monster: Towards a social model of 'child protection'. Fam. Relatsh. Soc. 2018, 7, 7-22. [CrossRef]

6. Gillies, V.; Edwards, R.; Horsley, N. Challenging the Politics of Early Intervention; Policy Press: Bristol, UK, 2017.

7. Broadhurst, K.; Alrouh, B.; Yeend, E.; Harwin, J.; Shaw, M.; Pilling, M.; Mason, C.; Kershaw, S. Connecting events in time to identify a hidden population: Birth mothers and their children in recurrent care proceedings in England. Br. J. Soc. Work 2015, 45, 2241-2260. [CrossRef]

8. Broadhurst, K.; Mason, C.; Bedston, S.; Alrouh, B.; Morriss, L.; McQuarrie, T.; Palmer, M.; Shaw, M.; Harwin, J.; Kershaw, S. Vulnerable Birth Mothers and Recurrent Care Proceedings; Final Main Report; Centre for Child and Family Justice Research: Lancaster, UK, 2017.

9. Broadhurst, K.; Mason, C. Birth Parents and the collateral consequences of court-ordered child removal: Towards a comprehensive framework. Int. J. Law Policy Fam. 2017, 31, 41-59. [CrossRef]

10. Broadhurst, K.; Mason, C. Child removal as the gateway to further adversity: Birth mother accounts of the immediate and enduring collateral consequences of child removal. Qual. Soc. Work 2020, 19, 15-37. [CrossRef]

11. Morriss, L. Haunted futures: The stigma of being a mother living apart from her child (ren) as a result of state-ordered court removal. Sociol. Rev. 2018, 66, 816-831. [CrossRef]

12. Schofield, G.; Moldestad, B.; Höjer, I.; Ward, E.; Skilbred, D.; Young, J.; Havik, T. Managing loss and a threatened identity: Experiences of parents of children growing up in foster care, the perspectives of their social workers and implications for practice. Br. J. Soc. Work 2011, 41, 74-92. [CrossRef]

13. Cox, P.; Barratt, C.; Blumenfeld, F.; Rahemtulla, Z.; Taggart, D.; Turton, J. Reducing recurrent care proceedings: Initial evidence from new interventions. J. Soc. Welf. Fam. Law 2017, 39, 332-349. [CrossRef]

14. Cox, P.; McPherson, S.; Mason, C.; Ryan, M.; Baxter, V. Reducing recurrent care proceedings: Building a local evidence base in England. Societies 2020, 10, 88. [CrossRef]

15. Roberts, L.; Maxwell, N.; Messenger, R.; Palmer, C. Evaluation of Reflect in Gwent; Final Report; CASCADE: Cardiff, UK, 2018. 
16. McCracken, K.; Priest, S.; FitzSimons, A.; Bracewell, K.; Torchia, K.; Parry, W.; Stanley, N. Evaluation of Pause; Department for Education: London, UK, 2017.

17. Boddy, J.; Bowyer, S.; Godar, R.; Hale, C.; Kearney, J.; Preston, O.; Wheeler, B.; Wilkinson, J. Evaluation of Pause; Research Report RR1042; Department for Education: London, UK, 2020.

18. Pause. Pause Framework, 1st ed.; Pause: London, UK, 2017.

19. Cox, P. Marginalized mothers, reproductive autonomy, and "repeat losses to care". J. Law Soc. 2012, 39, 541-561. [CrossRef]

20. Fraser, N.; Honneth, A. Redistribution or Recognition? A Political-Philosophical Exchange; Verso: London, UK, 2003.

21. Broadhurst, B.; Shaw, M.; Kershaw, S.; Harwin, J.; Alrouh, B.; Mason, C.; Pilling, M. Vulnerable birth mothers and repeat losses of infants to public care: Is targeted reproductive health care ethically defensible? J. Soc. Welf. Fam. Law 2015, 37, 84-98. [CrossRef]

22. Honneth, A. The I in We; Polity Press: Cambridge, UK, 2012.

23. Fraser, N. Recognition without ethics? Theory Cult. Soc. 2001, 18, 21-42. [CrossRef]

24. Butler, J. Undoing Gender; Routledge: Abingdon, UK, 2004.

25. Houston, S. Empowering the shamed self: Recognition and critical social work. J. Soc. Work 2016, 16, 3-21. [CrossRef]

26. Turney, D. A relationship-based approach to engaging involuntary clients: The contribution of recognition theory. Child Fam. Soc. Work 2012, 17, 149-159. [CrossRef]

27. Fincham, B. The Sociology of Fun; Palgrave Macmillan: London, UK, 2016.

28. Tyler, I.; Slater, T. Rethinking the sociology of stigma. Sociol. Rev. Monogr. 2018, 66, 721-743. [CrossRef]

29. Mazzei, A.Y.; Jackson, L.A. Thinking with Theory in Qualitative Research. Viewing Data across Multiple Perspectives; Routledge: Abingdon, UK, 2012.

30. Craig, P.; Matthews, L.; Moore, L.; Simpson, S. Developing and Evaluating Complex Interventions: Draft of Updated Guidance; University of Glasgow: Glasgow, UK, 2019.

31. Riessman, C.K. Stigma and everyday resistance practices. Childless women in South India. Gend. Soc. 2000, 14, 111-135. [CrossRef]

32. Thomson, R.; Holland, J. Imagined adulthood: Resources, plans and contradictions. Gend. Educ. 2002, 14, 337-350. [CrossRef]

33. Boddy, J.; Bakketeig, E.; Østergaard, J. Navigating precarious times? The experience of young adults who have been in care in Norway, Denmark and England. J. Youth Stud. 2020, 23, 291-306. [CrossRef]

34. Staunæs, D.; Kofoed, J. Hesitancy as ethics. Reconceptualizing Educ. Res. Methodol. 2015, 6, 24-39.

35. Join-Lambert, H.; Boddy, J.; Thomson, R. The experience of power relationships for young people in care. Developing an ethical, shortitudinal and cross-national approach to researching everyday life. Forum Qual. Soc. Res. 2020, 21, 1-22.

36. Fraser, N. Women, welfare and the politics of need interpretation. Hypatia 1987, 17, 103-121. [CrossRef]

37. Galloway, A.; Boland, B.; Williams, G. Mental health problems, benefits and tackling discrimination. Br. J. Psychiatry Bull. 2018, 42, 200-205. [CrossRef]

38. Greenstein, A.; Burman, E.; Kalambouka, A.; Sapin, K. Construction and deconstruction of 'family' by the 'bedroom tax'. Br. Politics 2016, 11, 508-525. [CrossRef]

39. Department for Education. Applying Corporate Parenting Principles to Looked-after Children and Care Leavers. Statutory Guidance for Local Authorities; DfE: London, UK, 2018.

40. Dalgleish, T.; Black, M.; Johnston, D.; Bevan, A. Transdiagnostic approaches to mental health problems: Current status and future directions. J. Consult. Clin. Psychol. 2020, 88, 179-195. [CrossRef] [PubMed]

41. Cleaver, H. Fostering Family Contact; The Stationery Office: London, UK, 2000.

42. Iyer, P.; Boddy, J.; Hammelsbeck, R.; Lynch-Huggins, S. Contact Following Placement in Care, Adoption, or Special Guardianship: Implications for Children and Young People's Well-Being. Evidence Review; Nuffield Family Justice Observatory: London, UK, 2020.

43. Boddy, J. The supportive relationship. In Social Pedagogy and Working with Children: Engaging with Children in Care; Cameron, C., Moss, P., Eds.; Jessica Kingsley: London, UK, 2011.

44. Harris, T.; Hodge, L.; Phillips, D. English Local Government Funding: Trends and Challenges in 2019 and Beyond; Institute for Fiscal Studies: London, UK, 2019. 
45. Jensen, T.; Tyler, I. Benefits broods: The cultural and political crafting of anti-welfare commonsense. Crit. Soc. Policy 2015, 35, 470-491. [CrossRef]

46. Butler, J. Rethinking vulnerability and resistance. In Vulnerability in Resistance; Butler, J., Gambetti, Z., Sabsay, L., Eds.; Duke University Press: Durham, UK, 2016.

47. Council of Europe/European Court of Human Rights. Guide on Article 8 of the European Convention on Human Rights. Right to Respect for Private and Family Life, Home and Correspondence. 2020. Available online: https://www.echr.coe.int/documents/guide_art_8_eng.pdf (accessed on 20 September 2020).

Publisher's Note: MDPI stays neutral with regard to jurisdictional claims in published maps and institutional affiliations.

(C) 2020 by the authors. Licensee MDPI, Basel, Switzerland. This article is an open access article distributed under the terms and conditions of the Creative Commons Attribution (CC BY) license (http://creativecommons.org/licenses/by/4.0/). 